
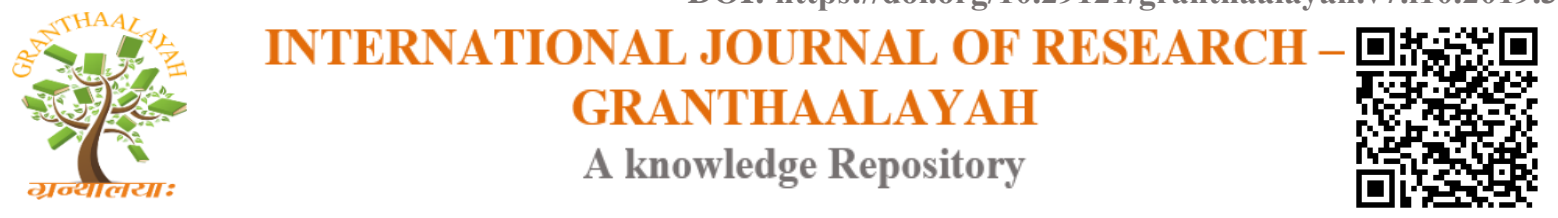

Social

\title{
SMART TOILET CONSTRUCTED UNDER CSR: STUDY FROM TAMIL
} NADU

\author{
Dr. Shankar Chatterjee *1 \\ ${ }^{* 1}$ Former Prof \&Head (CPME), NIRD \&PR, Hyderabad-500 030, Telangana, India
}

\begin{abstract}
When human waste (feces) is not managed well, it pollutes water, food, and soil with germs and leads to diarrhea and other health problems. Using toilets prevents germs from getting into the environment and protects the health. Keeping in mind of the issue, the World Toilet Organization was established in 2001 with the aim to break the taboo around toilets and the sanitation crisis. Since 2001, World Toilet Organization lobbied governments, public and private sector stakeholders and the international community to prioritize sanitation in the development agenda. In India, in addition to Government of India and respective state Governments, one NGO viz., Gramalaya based on its office at Tiruchirappalli district of Tamil Nadu has been doing praiseworthy work as Gramalaya has been promoting SMART toilets (S - Safe and Sustainable, M - Maintainable, A - Affordable, R - Recyclable (waste), T - Technically perfect) under the leadership of its Founder Chairman Shri. S. Damodaran. Also, Gramalaya has been producing sustainable sanitary pads (washable) for the menstrual girls and women for their better health and hygiene under the trade name of FeelFree. In this research article, activities of Gramalaya by constructing SMART toilets were studied by the author at Budalur block of Thanjavur district also locally known as Tanjore district of Tamil Nadu in September 2019. These toilets were under Corporate Social Responsibility (CSR), funded by Lion Dates Impex Private limited. Lion Dates Company is India's largest date processing and trading company. The Company has factories located in Tamil Nadu. The Lion Dates brand is available across 29 states and 7 union territories in India.

It is also suggested that SMART toilet concept may be replicated other parts of the country based on local, social, cultural and backward and forward linkages.
\end{abstract}

Keywords: Gramalaya; Sustainable Sanitary Pad; Toilet; Tamil Nadu and World Toilet Organization.

Cite This Article: Dr. Shankar Chatterjee. (2019). "SMART TOILET CONSTRUCTED UNDER CSR: STUDY FROM TAMIL NADU." International Journal of Research Granthaalayah, 7(10), 263-268. https://doi.org/10.29121/granthaalayah.v7.i10.2019.395. 


\section{Introduction}

When human waste (feces) is not managed well, it pollutes water, food, and soil with germs and leads to diarrhea and other health problems. Using toilets prevents germs from getting into the environment and protects the health. Keeping in mind of the issue, the World Toilet Organization was established in 2001 with the aim to break the taboo around toilets and the sanitation crisis. Since 2001, World Toilet Organization lobbied governments, public and private sector stakeholders and the international community to prioritize sanitation in the development agenda. In India, for promoting of sanitary latrine, in addition to Government of India and respective state Governments, one NGO viz., Gramalaya based on its office at Tiruchirappalli district of Tamil Nadu has been doing praiseworthy work as Gramalaya has been promoting SMART toilets ( $\mathrm{S}$ Safe and Sustainable, M - Maintainable, A - Affordable, R - Recyclable (waste), T - Technically perfect) under the leadership of its Founder Chairman Shri S. Damodaran. Also, Gramalaya has been producing sustainable sanitary pads (washable) for the menstrual girls and women for their better health and hygiene. Sanitation is a global issue mostly in the developing countries and keeping in mind of the issue, the World Toilet Organization was established in 2001 with the aim to break the taboo around toilets and the sanitation crisis. Since 2001, World Toilet Organization lobbied governments, public and private sector stakeholders and the international community to prioritize sanitation in the development agenda. According to World Toilet Organization, "Around one billion people in our world today face the indignity of defecating in the open (as per 2015). A lack of clean and safe toilets at schools leads to higher dropout among girls once they reach puberty. Diarrheal diseases - a direct consequence of poor sanitation - kill more children every year than AIDS, malaria and measles combined" (worldtoilet.org/what-we-do/why-toilets/5/3/19). Further, according to the World Toilet Organization, clean and safe toilets help more girls to attend schools and increase attendance rates.

\section{Materials and Methods}

To address the issue at grassroots level many organizations have been working at different levels in India like awareness creation, promotion of sanitary toilets, producing of cheap sanitary pads etc. And one such organization viz., Gramalaya of Tamil Nadu with its office at Tiruchirappalli district may be mentioned. Gramalaya has been promoting SMART toilets and sustainable sanitary pads for girls and women by producing themselves in Tamil Nadu and popularizing among the people are discussed here.

Gramalaya was established in 1987 with a group of committed youths in the field of rural development under the leadership of Shri S. Damodaran, Chief Executive Officer (CEO) and Founder Chairman. Gramalaya has got its legal entity by registering under the Indian Trust Act of 1882 in the year1987. The main objective of Gramalaya is to work for the amelioration of socially downtrodden people under the integrated rural development approach. Since 1987, Gramalaya has been operating in Thottiyam, Thathaiengarpet and Thuraiyur blocks and in the slums of Tiruchirappalli city. Health and hygiene education, promotion of self-help groups among rural, urban and tribal women, construction of low-cost latrines and safe water supply through microcredit are the major activities of the organization (gramalaya.in). Further, it may be mentioned that, Gramalaya is one of the approved national Key Resource Centers of the Ministry of Drinking Water and Sanitation, Government of India for water and sanitation for South India. Also, 
Gramalaya is supporting Government of Tamil Nadu for its PVP - Pudhu Vazhvu Project funded by World Bank as its technical support unit in providing training and capacity building program for sanitation.

According to the officials of Gramalaya, it has experimented successfully innovative models like Micro-finance for Sanitation, Child Friendly toilets, Community Managed pay and use latrines; school health program with working experience in rural, urban, tribal and coastal regions. Thus, the organization has shown the path for development among the common persons. Further, the school health intervention through child-to-child approach, cost effective toilet models developed at the Centre for Toilet Technology and Training established by Gramalaya, microfinance for sanitation models, IEC materials developed by Gramalaya with WaterAid, UNICEF and Arghyam fund are other achievements of Gramalaya.

Gramalaya field tested several rural and urban sanitation models for individual households and schools. According to data provided by the Gramalaya, the Organization has constructed more than 1,00,000 toilets with funding support under CRSP, TSC, NBA schemes of Government and with the grant support of WaterAid, Arghyam and UNICEF. Its toilet popularly known as SMART toilet is praiseworthy innovation. Length and width of each toilet are 8 feet and 4 feet respectively with latrine (outside two pits) and in the toilet itself there is bath room with water storage facility. Thus, after the toilet one need not go for washing for bathing in other place. Also, provision has been made for keeping hand wash soap etc. in one corner of the SMART toilet in about five feet height, a permanent structure.

\section{Salient features of a SMART Toilets}

- It should be used as a toilet cum bathroom and user-friendly toilet.

- It is having hand washing facilities.

- All hygiene kits may be kept inside the toilet.

- There are provisions for water storage points for cleaning purpose, as well as proper ventilation facility.

- It is having facility for sanitary napkin disposal.

- Further, there are provisions for lighting, twin pit-toilets for sustainable use and maintenance and waste can be recycled

- Such toilet is having with roof facilities to protect from sun and rain

\section{Sanitary Pad}

Another important activity of Gramalaya for the welfare of the society is innovation of cheapest reusable cloth pad for menstrual hygiene management, which is called as FeelFree reusable cloth pads, under the banner of FeelFree title as registered trade mark. Gramalaya felt the need to produce such clothes because it worked with adolescent girls in the Government schools of Tamil Nadu with the grant-support of Bank of America Merrill Lynch Capital under its corporate social responsibility (CSR) initiatives. It is pertinent to mention that, according to the WHO survey conducted in October 2017 carried out across India including 35 cities viz., Bengaluru, Chennai, Cuttack, Delhi, Indore, Jaipur, Kanpur, Kolkata, Ludhiana, Mumbai, Ranchi, Srinagar, Surat, Thiruvananthapuram etc., women respondents were contacted to get an idea about issues related to women. It has been revealed that about 43 percent of Indian women did not have access to sanitary essentials at the beginning of periods, while 36 percent felt uncomfortable in buying them 
with other customers around. Further, according to the survey report around 67 percent women have had to borrow a sanitary essential from a friend, colleague or family member. More than 45 percent women opined that menstruation was still considered a taboo in the society and 36 percent felt uncomfortable while buying sanitary essentials from a chemist shop in the presence of other customers.

To address these issues, sanitary pads were launched by the Gramalaya. These pads are cloth pads to absorb the menstrual flow during a woman's period, an alternative to disposable sanitary napkins or to reusable menstrual cups. Further, these are less expensive than disposable pads, reduce the amount of waste produced and also have health benefits, (feelfreeclothpads.com).

According to the officials of Gramalaya, the disposable pads available in the markets are whitened with chlorine bleach, which produces a toxic byproduct called dioxin. Further, disposables pads also contain plastic chemicals and pesticide residue, but the sustainable pads made by Gramalaya are free from all these.

FeelFree Reusable Cloth Pads: For the benefit of readers steps for using the pads as mentioned by the organization are mentioned so that it can be promoted in other parts of the country among adolescent girls.

- First Step: As a first step, used cloth pads have to be soaked in ordinary clean water for about 30 minutes

- Second Step: Washing soap or washing powder should be used to wash the clothes.

- Third Step: Brush etc. should not be used during washing.

- Fourth Step: It should be rinsed with normal water.

- Fifth Step: The pads have to be dried in direct sunlight.

- Sixth Step: Please see the washed cloth pads should be safe from pests and dusts while ii is in sunlight

- Lastly: Pouch is available for keeping used cloth pad while in working place/school/colleges and after returning to home it can be washed for re-used.

The officials of Gramalaya during filed study informed that along with SMART toilet each family is given one packet of sustainable sanitary pad (trade name is FeelFree) containing four numbers which can be used by girls/ ladies in menstrual stage up to two years and these are washable also. Anyway, SMART toilets were constructed under Corporate Social Responsibility (CSR), funded by Lion Dates Impex Private limited which is India's largest date processing and trading company. The Company has factories located in the city of Tiruchirapalli and nearby villages. The Lion dates are available across 29 states and 7 union territories in India. The Company believes in the principle of corporate social responsibility (CSR) so arranging fund for SMART toilets, and provides employment to rural women and to differently-abled people (wikipedia.org/wiki/Lion_Dates).

\section{Results and Discussions}

To get an idea about utility and usefulness of SMART toilet, a study was carried out at Mahadhavapuram village, Budalur block of Thanjavur district also locally known as Tanjore district of Tamil Nadu in September 2019 and the cases are presented here. It is pertinent to 
mention that the village is located about 30 kilometers away from Trichy town and almost same distance is from Thanjavur town. Thanjavur district is also locally known as Tanjore district. The district is spread over to an area of 3396.57 square kilometers. It consists of three divisions Thanjavur, Kumbakonam, Pattukottai and nine Taluks of Thanjavur, Kumbakonam, Papanasam, Pattukottai, Peravurani, Orathanadu, Thiruvidaimarudur, Thiruvaiyaru and Budalur. Thanjavur district is known as 'the Rice Bowl of Tamil Nadu' because of its agricultural activities in the delta region of river Cauvery. According to 2011 census, population of the district was 24 lakh with the population density of 708 persons per square kilometer. The district had high literacy rate -82.72 per cent (thanjavur.nic.in/about-district/13/10/19).

The cases of the beneficiaries provided with SMART toilet sponsored under CSR of Lion Dates implemented by Gramalaya are presented below. The beneficiaries were contacted by visiting the village in September 2019 and Participatory Rural Appraisal (popularly known as PRA methodology) was used to collect data. In addition to the toilet, each household was provided with one FeelFree Pad containing four members for using during menstrual period. As mentioned already these pads are washable, so reusable. In the village, altogether 26 families were provided with SMART toilets in 2018, of which five cases (little more than 20 percent beneficiaries) were studied and presented here.

Case - i): Mrs. Irudhayamary of Mahadhavapuram village, Budalur block of Thanjavur district (31 years/ $10^{\text {th }}$ pass/ Diploma in Nursing) belonging to Backward Caste (BC) expressed her happiness while the family was provided with a SMART toilet in September 2018 (exactly one year completed when the study was carried out). She and her husband with three daughters (all below 10 years) had tough time to ease out natural call whether day or night as they had to go 0.5 kilometer away near Cauvery river but the issue was totally resolved after the toilet constructed in September 2018. While the study was carried out exactly one year was over and all were using the toilet blissfully. As informed by the officials of Gramalaya, total cost of the toilet was Rs.21,500.00 of which Rs.18,000.00 was from Lion Dates (CSR share) and Rs.3,500.00 was beneficiary's contribution. Mrs. Irudhayamary was also provided with one FeelFree pad containing four numbers for using during menstrual period. She further informed that her husband as driver was earning a sum of Rs.10,000.00 per month which is the only source of income and the family did not have any agricultural land.

ii) Mrs. Mariam Bibi (65 years/ illiterate) was provided with the toilet in September 2018. She was widow and had four children - two sons and two daughters. One son with his wife and four girls children (daughters) were staying with her. The son was eking out their livelihood by selling mutton. Her other three children (one son and two daughters) were married and son was staying separately.

iii) Mrs. Deva Marry (60 years/ $8^{\text {th }}$ pass) belonging to BC, had three children (1 daughter and 2 sons). One son after marriage stayed separately and another son (stayed with the family) was working in Lion Dates factory, not married till the day of study (20th September 2019). Mrs. Deva Marry and her husband (62 years) were earning by making housing roof (thatch) through coconut leaves, a skillful work, albeit earning per month was Rs.1000.00 on an average. Also both were working as agricultural labourer. The family had one ace of agricultural land but only in Kharif they could cultivate. And as animal assets they had one cow (6/7 months milk available) and three sheep. 
The other two persons who were contacted during field study were - iv)Mrs. Vanitha (40 years/ $10^{\text {th }}$ pass) was provided with SMART toilet and with husband and three daughters ( all below 10 years and schooling going) were using the same and v) Miss. Anandi (25 years, completed Degree) was also a beneficiary. Miss Anandi was working in Lion Dates factory but parents were agricultural labourer, so after her earning family had better days.

All the persons were provided with FeelFree Pad each containing four in number and the SMART project was completed in September 2018.

\section{Conclusions and Recommendations}

During the course of study, the women members informed that SMART toilet and sanitary pads had greatly helped them to live with honour, dignity and hygienically. Because earlier they had to go to near Cauvery River to ease out natural call which from social and health points of view are not good. The FeelFree sanitary pad is important for their health, hygiene, safety and dignity points of view. It is therefore, suggested that such model may be replicated to other parts of the country based on local, social and cultural situation.

\section{References}

[1] http://worldtoilet.org/10/10/19

[2] http://www.gramalaya.in/about_gramalaya.php

[3] https://thanjavur.nic.in/about-district/13/10/19

[4] https://en.wikipedia.org/wiki/Lion_Dates/12/10/19

*Corresponding author.

E-mail address: shankarjagu@ gmail.com 